\title{
A pH-Responsive System Based on Fluorescence Enhanced Gold Nanoparticles for Renal Targeting Drug Delivery and Fibrosis Therapy
}

This article was published in the following Dove Press journal: International Journal of Nanomedicine

\section{Xuandi Lai ${ }^{1}$ \\ Xinran Geng ${ }^{2}$ \\ Lishan Tan' \\ Jianqiang $\mathrm{Hu}^{2}$ \\ Shubin Wang'}

'Department of Oncology, Shenzhen Key Laboratory of Gastrointestinal Cancer Translational Research, Peking University Shenzhen Hospital, Shenzhen Peking University-the Hong Kong University of Science and Technology Medical Center, Shenzhen 518036, People's Republic of China; ${ }^{2}$ Nanobiological Medicine Center, Key Laboratory of Fuel Cell Technology of Guangdong Province, School of Chemistry and Chemical Engineering, South China University of Technology, Guangzhou 510640, People's Republic of China

Correspondence: jianqiang $\mathrm{Hu}$ Nanobiological Medicine Center, Key Laboratory of Fuel Cell Technology of Guangdong Province, School of

Chemistry and Chemical Engineering, South China University of Technology, No. 38I, Wushan Road, Tianhe District, Guangzhou 510640, People's Republic of China

Tel +86-I86 657| 1833

Email jqhusc@scut.edu.cn

Shubin Wang

Department of Oncology, Shenzhen Key Laboratory of Gastrointestinal Cancer

Translational Research, Peking University Shenzhen Hospital, Shenzhen Peking University-the Hong Kong University of Science and Technology Medical Center, No. I I20, Lianhua Road, Futian District, Shenzhen 5I8036, People's Republic of China

Tel $+86-755-83923333$

Fax +86-755-83061340

Email wangshubin2013@I63.com
Background: Stimuli-responsive gold nano-assemblies have attracted attention as drug delivery systems in the biomedical field. However, there are challenges achieving targeted delivery and controllable drug release for specific diseases.

Materials and Methods: In this study, a glutathione (GSH)-modified fluorescent gold nanoparticle termed AuLA-GSH was prepared and a $\mathrm{Co}^{2+}$-induced self-assembly drug delivery platform termed AuLA-GSH-Co was constructed. Both the $\mathrm{pH}$-responsive character and drug loading behavior of AuLA-GSH-Co were studied in vitro. Kidney-targeting capability was investigated in vitro and in vivo. Finally, the anti-fibrosis efficiency of AuLAGSH-Co in a mouse model of unilateral ureteral obstruction (UUO) was explored.

Results: AuLA-GSH-Co was sensitive to $\mathrm{pH}$ changes and released $\mathrm{Co}^{2+}$ in acidic conditions, allowing it to have controllable drug release abilities. AuLA-GSH-Co was found to improve cellular uptake of $\mathrm{Co}^{2+}$ ions compared to $\mathrm{CoCl}_{2}$ in vitro. AuLA-GSH exhibited specific renal targeting and prolonged renal retention time with low non-specific accumulation in vivo. Moreover, the anti-fibrosis efficiency of AuLA-GSH-Co was higher compared to $\mathrm{CoCl}_{2}$ in a mouse model of unilateral ureteral obstruction (UUO).

Conclusion: AuLA-GSH-Co could greatly enhance drug delivery efficiency with renal targeting capability and obviously relieve renal fibrosis, providing a promising strategy for renal fibrosis therapy.

Keywords: gold nanoparticles, self-assembly, $\mathrm{pH}$ sensitivity, drug delivery, renal fibrosis

\section{Introduction}

Nanotechnology has promoted new vitality in the biomedicine field. ${ }^{1}$ Various nanoparticles (NPs), such as polymer NPs, magnetic NPs, quantum dots, carbon nanotubes and metal NPs have been studied in relation to antibacterial effects, leukemia treatment and drug delivery. ${ }^{2,3}$ Specifically, the application of metal NPs, especially gold NPs (AuNPs), has attracted attention due to versatile surface modifications, simple preparation and good biocompatibility. ${ }^{4,5}$ However, AuNPs as drug carriers still face the challenges of low drug loading efficiency, short halflife and high non-specific accumulation. ${ }^{6,7}$ Thus, appropriate surface modifications are necessary to broaden the application of AuNPs. ${ }^{6,-10}$ Small molecule polymers and polypeptides were added to the surfaces of AuNPs with the goal of optimizing their properties. ${ }^{8,11,12}$ Glutathione (GSH) is an ideal surface coating for AuNPs that prolongs the half-life in blood circulation and possess particles with negative charges that escape macrophage phagocytosis. ${ }^{13,14}$ At the same time, abundant 
lone pair electrons from $-\mathrm{COOH}$ and $-\mathrm{NH}_{2}$ residues in GSH-modified AuNPs may interact with drugs through coordination interaction, especially in the case of transition metal ions, to form a self-assembled drug delivery system. ${ }^{15}$ Since the coordinate bond forms a weak interaction, it is sensitive to $\mathrm{pH}$ and can be beneficial to realize controllable drug release. ${ }^{16}$ Thus, GSH-modified AuNPs exhibit superior properties when it comes to drug delivery.

Renal fibrosis is a common, final phase of chronic kidney disease (CKD). The progression of fibrosis will increase renal dysfunction, leading to end-stage renal disease. ${ }^{17,18}$ Traditionally, controlling systemic blood pressure, hyperglycemia or dyslipidemia are strategies for renal fibrosis therapy. ${ }^{19}$ However, treatment to slow down or even reverse the development of renal fibrosis remains a challenge. Recently, work has focused on genes or proteins that may play a role in alleviating fibrosis, leading to complex and expensive studies. ${ }^{20-22}$ However, biomolecules are prone to degradation or non-specific enrichment during circulation in vivo, resulting in low drug concentrations in kidney and increased side effects. Therefore, designing a renal targeting delivery system containing an accessible drug with controllable release is crucial to solve these challenges.

Studies have confirmed that GSH specifically targets the kidney. ${ }^{23,24}$ Moreover, cobalt ion $\left(\mathrm{Co}^{2+}\right)$ is reported to be a hypoxia-inducible factor (HIF) activator ${ }^{25,26}$ Cobalt also slows down tubulointerstitial damage and maintains the integrity of capillary networks in rat fibrosis models. ${ }^{27}$ Thus, taking advantage of GSH, which possesses renal targeting ability and abundant lone pairs, as well as $\mathrm{Co}^{2+}$ may contribute to an efficient drug delivery system for renal fibrosis therapy.

In this study, a GSH-modified fluorescent gold nanoparticle termed AuLA-GSH was prepared and a $\mathrm{Co}^{2+}$ induced self-assembly drug delivery platform termed AuLA-GSH-Co was constructed for renal fibrosis targeting therapy. GSH modifications enhanced the fluorescence of AuLA, which is beneficial for tracing drug delivery. In addition, AuLA possesses renal targeting ability, which can decrease non-specific drug accumulation. AuLAGSH-Co was shown to be sensitive to $\mathrm{pH}$ due to the relatively weak coordination interaction between AuLAGSH and $\mathrm{Co}^{2+}$. The drug was released under acidic conditions, which is consistent with the microenvironment of the fibrotic site. The cellular uptake of $\mathrm{Co}^{2+}$ in AuLAGSH-Co was significantly higher than $\mathrm{CoCl}_{2}$ uptake by cells. AuLA-GSH showed noticeable renal accumulation for an extended period of time (at least $12 \mathrm{~h}$ ) with low reticuloendothelial system (RES) retention in vivo. Meanwhile, AuLA-GSH-Co significantly improved the anti-fibrosis efficiency in unilateral ureteral obstruction (UUO) mice.

\section{Materials and Methods \\ Materials}

Chloroauric acid $\left(\mathrm{HAuCl}_{4} \cdot 3 \mathrm{H}_{2} \mathrm{O}\right)$, reduced glutathione (GSH), copper chloride dihydrate $\left(\mathrm{CuCl}_{2} \cdot 2 \mathrm{H}_{2} \mathrm{O}\right)$, cobalt chloride hexahydrate $\left(\mathrm{CoCl}_{2} \cdot 6 \mathrm{H}_{2} \mathrm{O}\right)$ and nickel chloride hexahydrate $\left(\mathrm{NiCl}_{2} \cdot 6 \mathrm{H}_{2} \mathrm{O}\right)$ were purchased from Sigma-Aldrich (USA). 1-ethyl-3-[3-(dimethylamino)propyl] carbodiimide hydrochloride (EDC) and N-hydroxysuccinimide (sulfoNHS) were purchased from Sangon Biotech Co., Ltd. (Shanghai, China). D,L-thioctic acid (LA) was purchased from Bioscience \& Technology Co., Ltd. All reagents were used as received unless stated otherwise.

Luminescence spectra were collected using a Hitachi F-4500 Fluorescence Spectrophotometer (Japan). The hydrodynamic size of nanoparticles was analyzed using a Malvern Nano-ZS Laser Particle Size Analyzer (UK). Transmission electron microscopy (TEM) measurements were performed using a $200 \mathrm{kV}$ JEOL 2010-F transmission electron microscope (Japan). Ultraviolet-visible (UVvis) absorption spectra were recorded using a Hitachi U-3010 UV-vis spectrophotometer. Thermogravimetric analyzer (TGA) curves were obtained using a Q600 SDT DTA-TG thermal analyzer (USA). Cellular uptake was measured using Agilent 7700S inductively coupled plasma-mass spectrometry (ICP-MS, USA). Fluorescent and hematoxylin and eosin (H\&E) stained images were captured using a Zeiss digital camera Axio Imager (Germany). In vivo and ex vivo fluorescent images were taken using a Bruker FX PRO imaging system (Rochester, NY, USA). Real-time polymerase chain reaction (RT-PCR) analysis using SYBRGreen assays (TaKaRa, Japan) was measured using a LightCycler 96 (Roche, Switzerland).

\section{Preparation of Fluorescent Gold Nanoparticles}

The synthesis of near-infrared fluorescent gold nanoparticles was performed as previously described. ${ }^{28}$ Briefly, $1.3 \mathrm{mg}$ of LA powder was dissolved in $3.9 \mathrm{~mL}$ of aqueous solution containing $10 \mu \mathrm{L}$ of $2 \mathrm{M} \mathrm{NaOH}$. The mixture was stirred at room temperature for $15 \mathrm{~min}$ and $40 \mu \mathrm{L}$ of $\mathrm{HAuCl}_{4}(2 \%$,w/v) was added dropwise under vigorous stirring. After another 5 
min of stirring, the mixture changed from light yellow to colorless, which indicated that $\mathrm{Au}^{3+}$ was reduced to $\mathrm{Au}^{+.29}$ Then, $80 \mu \mathrm{L}$ of ice-cold sodium borohydride aqueous solution (50 $\mathrm{mM}$ ) was slowly added to the mixture, and it gradually changed from colorless to reddish brown. The reaction solution was stirred overnight at room temperature to obtain LA covered gold nanoparticles AuLAs. The resulting solution was centrifuged and purified using a $10 \mathrm{kDa}$ ultrafiltration centrifugation tube to remove excess LA molecules. Purified nanoparticles were re-dispersed in $\mathrm{pH} 7.4 \mathrm{PBS}$ stored in a $4^{\circ} \mathrm{C}$ refrigerator for later use. The concentration of AuLA solution was determined using a UV-vis spectrophotometer.

\section{GSH Modification of AuLAs}

Surface modifications of AuLAs containing GSH were performed using a covalent cross-linking reaction between the $-\mathrm{COOH}$ group on AuLA and the $-\mathrm{NH}_{2}$ group on GSH. First, $20.0 \mathrm{mg}$ of GSH powder, $18.8 \mathrm{mg}$ of EDC powder and $28.0 \mathrm{mg}$ of sulfo-NHS powder were dissolved in $10 \mathrm{~mL}$ of pure water. The mixture was gently stirred for $12 \mathrm{~h}$ in a $50^{\circ} \mathrm{C}$ water bath. Then, the solution was cooled to room temperature and dropped to freshly prepared AuLA solution. GSH-modified gold nanoparticles AuLAGSHs were obtained after $12 \mathrm{~h}$ of a light-sensitive reaction in an ice bath. Finally, the $\mathrm{pH}$ of the product solution was adjusted to 4-6 following 10,000 rpm centrifugation for 10 min to remove excess reactants. Purified AuLA-GSHs were re-dispersed in $\mathrm{pH}$ 7.4 PBS.

\section{Ion-Induced Fluorescence Switch System and Drug Loading}

$\mathrm{CuCl}_{2} \cdot 2 \mathrm{H}_{2} \mathrm{O}, \mathrm{CoCl}_{2} \cdot 6 \mathrm{H}_{2} \mathrm{O}$ and $\mathrm{NiCl}_{2} \cdot 6 \mathrm{H}_{2} \mathrm{O}$ solids were weighed and dissolved in ultra-pure water to form a 10 $\mathrm{mM}$ of metal ion solution. Then, $10 \mu \mathrm{L}$ of the metal ion solution was added to $100 \mu \mathrm{L}$ of AuLA-GSH $(20 \mathrm{mM})$ under ultrasonic and the fluorescence spectra of the mixed solution were characterized (voltage: $750 \mathrm{~V}$, excitation: $540 \mathrm{~nm}$ ). The $\mathrm{pH}$ of each mixture was set to 6.0 or 7.4 using $\mathrm{HCl}$ or $\mathrm{NaOH}$. Fluorescence intensities were measured using the same conditions mentioned above.

Under ultrasonic conditions, different volumes $(0-100 \mu \mathrm{L})$ of $10 \mathrm{mM} \mathrm{CoCl}_{2}$ were mixed in AuLA-GSH solution $(100 \mu \mathrm{L}$, $20 \mathrm{mM}$ ), and mixtures were incubated at room temperature for $30 \mathrm{~min}$. Then, the fluorescence spectra of each mixture were measured. The loading amount and rate of $\mathrm{Co}^{2+}$ for each sample were obtained by dissolving prepared AuLA-GSH$\mathrm{Co}(\mathrm{x})$ ( $\mathrm{x}$ represents the adding volume $\mathrm{Co}^{2+}$ ) in fresh aqua regia and determining the concentrations of $\mathrm{Au}^{3+}$ and $\mathrm{Co}^{2+}$ through ICP-AES.

\section{Cell Lines and Animals}

The proximal tubule NRK-52E and renal fibroblast NRK49F cell lines were purchased from American Type Culture Collection (ATCC, VA, USA). Balb/c and nude mice were purchased from the Guangdong Experimental Animal Center. All experiments were approved by the Animal Research Ethics Committee of Peking University Shenzhen Hospital and were conducted in accordance with the regulations and protocols of the Animal Laboratory Center of Peking University Shenzhen Hospital.

\section{Cytotoxicity Assays}

NRK-52E and NRK-49F cells were cultured in Dulbecco's Modified Eagle Medium (DMEM) containing 10\% FBS, penicillin $(100 \mathrm{U} / \mathrm{mL})$ and streptomycin $(100 \mathrm{mg} / \mathrm{mL})$ in a $5 \%$ $\mathrm{CO}_{2}, 95 \%$ humidity and $37^{\circ} \mathrm{C}$ incubator. Logarithmically growing cells were detached from plates using trypsin and plated to 96-well plates. After $24 \mathrm{~h}$, AuLA-GSH stock solutions with different concentrations (10-400 mM) were added to the cells and co-cultured for 12,24 or $36 \mathrm{~h}$. Finally, $10 \mu \mathrm{L}$ of CCK-8 solution was added to each well and cultured for $2 \mathrm{~h}$ at $37^{\circ} \mathrm{C}$. Cell viability based on optical density (OD) was calculated as follows: cell viability $=(\mathrm{OD}$ in the intervention wells blank wells $) /($ OD in the control wells - blank wells $) \times 100 \%{ }^{30}$ Viabilities of cells co-cultured with different concentration of $\mathrm{CoCl}_{2}(0-40 \mu \mathrm{M})$ for 12,24 or $36 \mathrm{~h}$ were also measured. Three sets of parallel samples were included in all experiments and each experiment was repeated three times. Wells not containing nanoparticles served as controls.

\section{Cellular Uptake Assays}

NRK-52E cells were co-cultured with AuLA or AuLA-GSH at $37^{\circ} \mathrm{C}$ for $3 \mathrm{~h}$ and then washed in ice-cold PBS 5 times to remove free nanoparticles. Subsequently, cells were fixed with a mixture of acetone and methanol at a 1:1 ratio for 10 min and stained with phenylindoles (DAPI) for $10 \mathrm{~min}$. Nanoparticle uptake was observed using a fluorescence microscope. Cell slices were prepared and observed using transmission electron microscopy (TEM).

To investigate the cellular uptake of $\mathrm{Co},{ }^{2+} \mathrm{NRK}-52 \mathrm{E}$ cells co-cultured with AuLA-GSH-Co or $\mathrm{CoCl}_{2}$ for different periods $(10,20,30,60,120,180,360,720,1440 \mathrm{~min})$ were collected. Then, cells were washed with ice-cold PBS to remove extra nanoparticles or $\mathrm{Co}^{2+}$ and digested with 
aqua regia. Concentrations of $\mathrm{Co}^{2+}$ were determined using inductively coupled plasma mass spectrometry (ICP-MS).

\section{Kidney Targeting Tests}

AuLA-GSH or AuLA solution was injected into balb/c mice intraperitoneally. The fluorescence distribution was observed on the in vivo imaging system $1 \mathrm{~h}$ post injection (p.i.). Mice injected with AuLA-GSH or AuLA were sacrificed at different time points (1, 3, 6 and $12 \mathrm{~h})$ to collect main organs (heart, liver, spleen, lung, kidney, thymus, small intestine, muscle and brain). The fluorescence of each organ was observed using an in vivo imaging system.

To further observe the specific location of AuLA-GSH in the kidney, mice injected with AuLA-GSH were sacrificed $6 \mathrm{~h}$ p.i. to harvest kidneys and frozen sections were immediately generated. Kidney slices were stained with AQP-1 antibody. The expression of AQP-1 antibody was detected by Alexa 488. Subsequently, the cell nucleus was stained with DAPI and observed using a fluorescence microscope.

\section{Modeling and Grouping of Unilateral Ureteral Obstruction (UUO) Mice}

Briefly, the modeling process of UUO mice was as follows: ${ }^{31}$ mice were anesthetized and excised on their left-back to remove the left kidney. Then, a 5-0 nylon surgical suture was tied at the end of the kidney and ligated twice. Finally, the ligated kidney was placed back into the mouse and the wound was sewn. Mice that underwent the same procedure but did not have their kidneys ligated were treated as the Sham operation (Sham) group. Specifically, mice were divided into the following groups: 1) Sham; 2) UUO mice + saline; 3) UUO mice + $\mathrm{CoCl}_{2}$; 4) UUO mice + AuLA-GSH-Co. The intervention material was intraperitoneally injected into the mice at a dose of $5 \mathrm{mg} / \mathrm{kg} /$ day. Mice were injected continuously for 7 days before surgery and sacrificed. Relevant samples were collected 14 days post operation.

\section{Histological Analysis}

Kidney samples were fixed in $10 \%$ paraformaldehyde at $4^{\circ}$ $\mathrm{C}$ overnight and embedded in paraffin for subsequent tissue staining. Tissue slices were stained using hematoxylin-eosin (H\&E), Masson and Sirius red. Moreover, Fibronectin and Collagen-I expression levels in kidney slices were stained with corresponding antibodies for each group. Tubular injury was scored ranging from 0 to 4: $0,<5 \%$; $1,5-25 \% ; 2,25-50 \% ; 3,50-75 \% ; 4,>75 \%$.

\section{Western Blotting}

Fresh kidney tissues were grounded and lysed using $1 \mathrm{mM}$ protease inhibitor lysate (RIPA) on ice. Total protein concentrations for each sample were quantified using the BCA Protein Assay Kit (EMD Millipore Corp, USA). Then, all protein samples were electrophoresed using 10\% SDSPAGE gels and transferred to PVDF membranes (pore size $0.2 \mu \mathrm{m}$. Merck Millipore Ltd, Germany). Membranes were blocked in 5\% skimmed milk for $1 \mathrm{~h}$ and incubated with relevant primary antibodies at $4{ }^{\circ} \mathrm{C}$ overnight. Finally, membranes were incubated with secondary antibodies labelled with HPR for $1 \mathrm{~h}$ and signals were detected by ECL (Thermo Fisher Scientific, Shanghai). Antibodies used in this study included anti-fibronectin (Sigma-Aldrich), anticollagen-I (Calbiochem), anti-NOX2, -NOX4 and anti-IL-6 (Santa Cruz Biotechnology), anti-MCP-1, anti-p-ERK, antiERK, anti-BAX (Cell Signaling Technology, Beverly, MA) and anti-ICAM (Abcam, USA). ${ }^{32}$

\section{RNA Extraction and Quantification}

RNA extraction and quantification were performed as follows: ${ }^{33}$ fresh kidney samples were grounded and lysed in TRIzol. Then, chloroform (1:5 volume ratio with TRIzol) was added, samples were mixed for $15 \mathrm{~s}$ and tissue homogenates were centrifuged in $12,000 \mathrm{~g}$ for 15 $\min$ at $4{ }^{\circ} \mathrm{C}$. Subsequently, isopropyl alcohol and ethanol were added to precipitate and purify RNA. The mRNA levels were quantitatively detected through RT-PCR and calculated after normalization with the endogenous control, GAPDH. Table S1 includes primer sequences used in RT-PCR analyses.

\section{Results and Discussion Morphology and Structure Characterization of AuLA and AuLA-GSH} AuLA was prepared using a "green" method where D, L-lipoic acid was used as reductant and surfactant. ${ }^{28}$ Asprepared AuLAs were uniform spherical particles with diameters of $2.5 \pm 0.3 \mathrm{~nm}$ observed by TEM (Figure S1). To target AuLA carrying medicine to the kidney, GSH was cross-linked to the surface of AuLA to obtain kidneytargeting nanoparticles AuLA-GSH. The morphology of AuLA-GSH was nearly the same as that of AuLA, which was spherical and contained a diameter of $2.9 \pm 0.6 \mathrm{~nm}$ 
(Figure 1A and B). The hydrodynamic size of AuLA-GSH (6.7 $\pm 0.8 \mathrm{~nm}$, PDI\%: 20.5) measured by DLS was slightly larger than AuLA (5.4 $\pm 0.7 \mathrm{~nm}, \mathrm{PDI} \%$ : 13.5), as shown in Figure 1C, indicating successful modification of GSH onto AuLA. This was due to the fact that the modified GSH molecule could interact with water molecules through hydrogen bonds in aqueous solution, so that nanoparticles were covered by a layer of hydrated molecules. ${ }^{34}$ AuLAGSH yielded red fluorescence with emission excitation peaks at $710 \mathrm{~nm}$ and $395 \mathrm{~nm}$, respectively (Figure 1D). Although the emission wavelengths of AuLA-GSH and AuLA were nearly the same (Figure S2), the fluorescence intensity of AuLA-GSH was significantly enhanced compared to AuLA under the same conditions (Figure 2A and B). This feature of AuLA-GSH is beneficial to its application in non-invasive tracking of drug delivery.

The FTIR spectra of GSH, AuLA and AuLA-GSH were measured (Figure 2C). A new vibration peak at
A

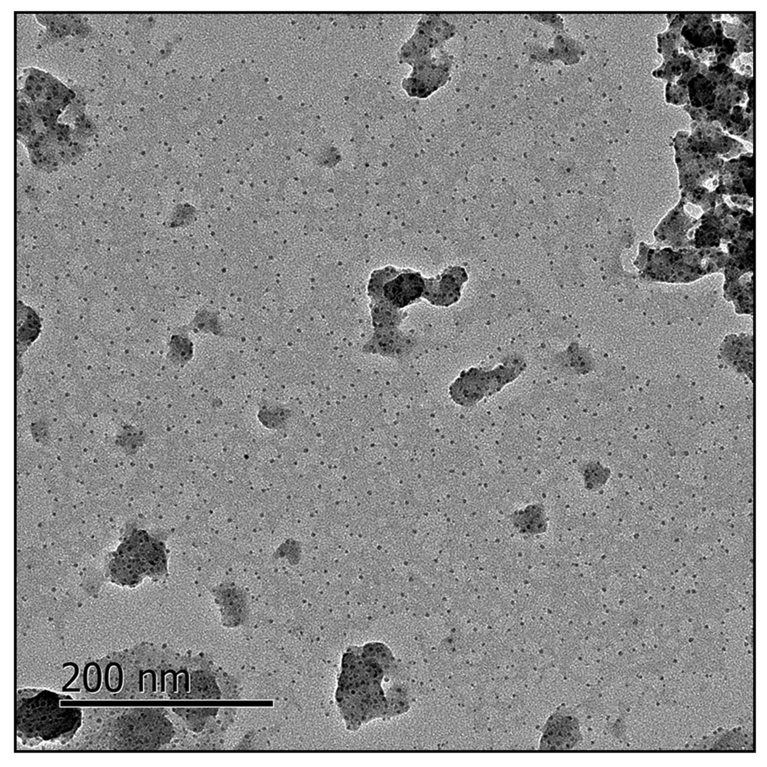

C

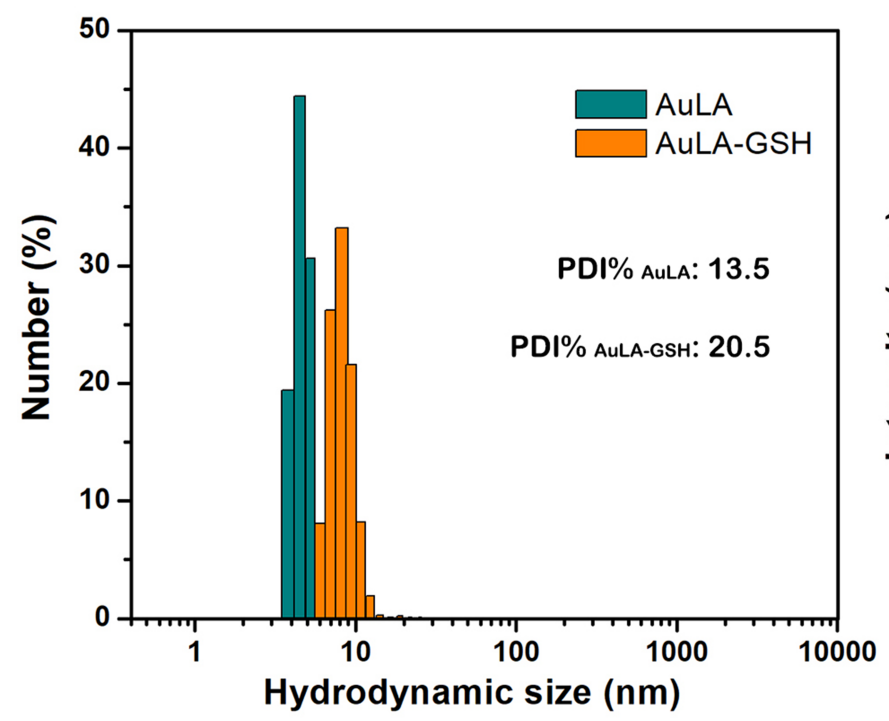

B

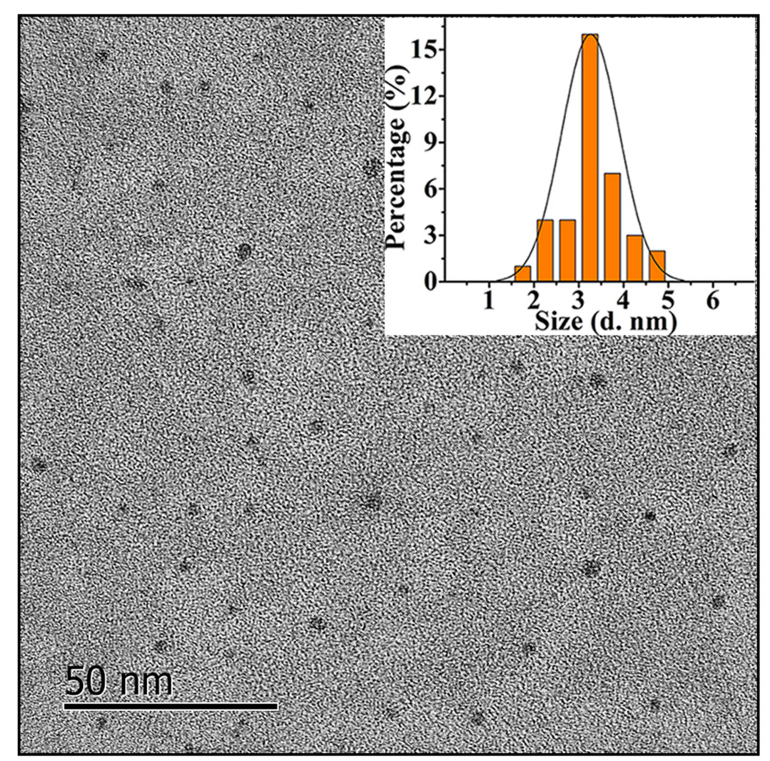

D

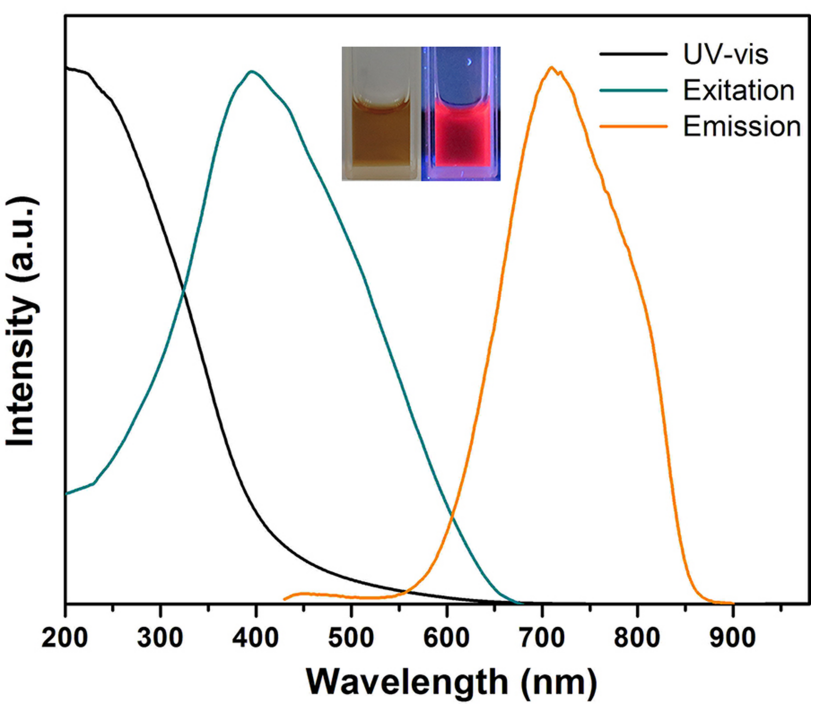

Figure I Characterization of AuLA and AuLA-GSH. TEM images of AuLA-GSH using a magnification of (A) 5000 and (B) 20,000, the inset of B is particle size distribution counted from the corresponding TEM image. (C) Hydrodynamic size distributions of AuLA and AuLA-GSH. (D) UV-vis absorption, fluorescence excitation and emission spectra of AuLA-GSH, insets are digital photos of AuLA-GSH solution taken under white light and UV light. 
A

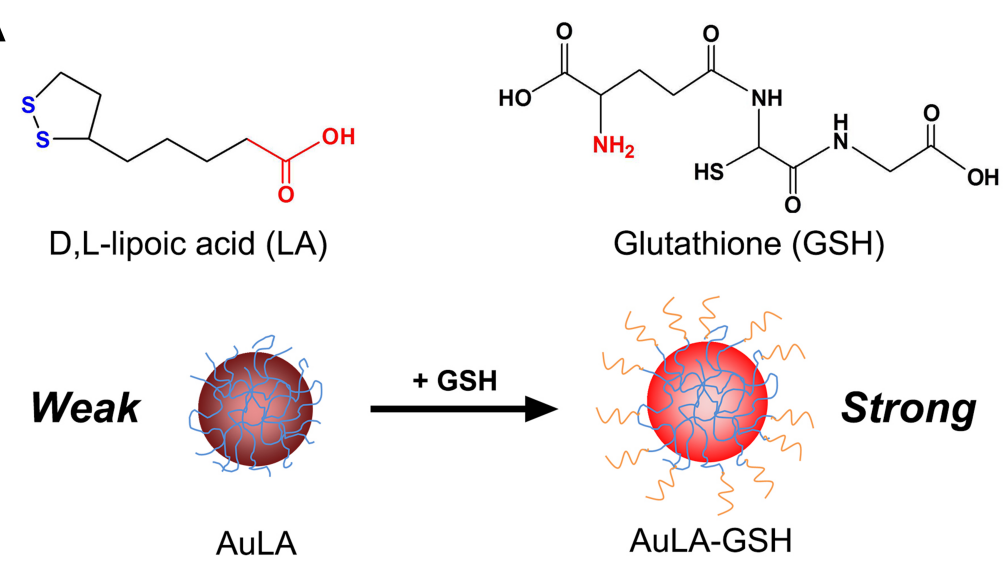

B

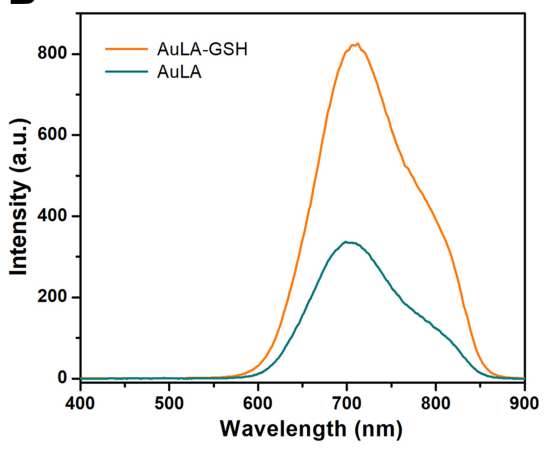

C

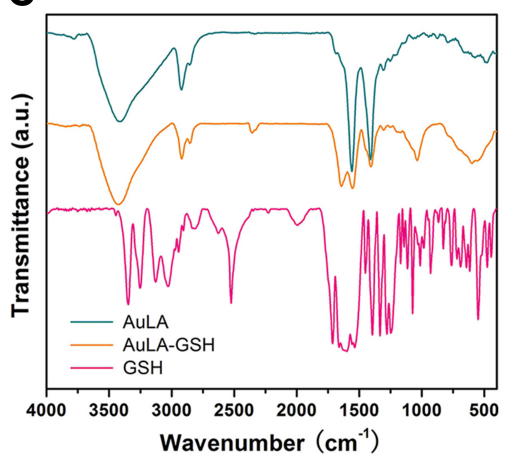

D

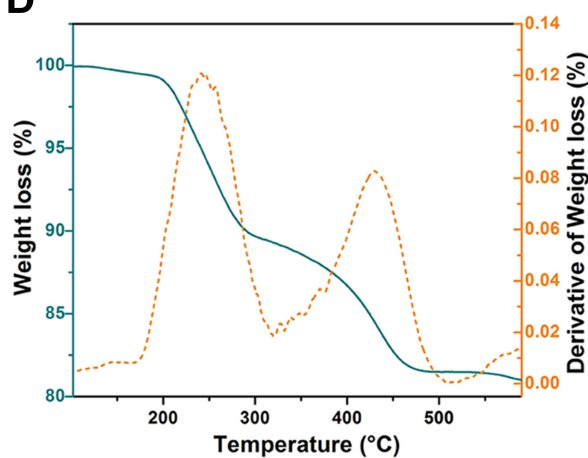

Figure 2 Fluorescence enhancement properties and structure characterization of AuLA-GSH. (A) The LA-coated gold nanoparticles (AuLAs) exhibit weak fluorescence while GSH-modified AuLA-GSH perform enhanced fluorescence. (B) Fluorescence emission spectra of AuLA and AuLA-GSH under the same particle concentration. The successful modification of GSH in AuLA was confirmed by (C) fourier transform infrared spectroscopy (FTIR) and (D) thermogravimetric analysis (TGA).

$2300 \mathrm{~cm}^{-1}$ appeared in the FTIR spectrum of AuLA-GSH compared to AuLA, which was consistent with the characteristic peak of the $-\mathrm{SH}$ group in $\mathrm{GSH}^{35,36}$ Moreover, two weight-loss platforms for AuLA-GSH detected by TGA indicated that there were two types of molecules in the nanoparticles (Figure 2D). These results further confirmed the successful modification of GSH on AuLA.

\section{Fluorescence Switch Features and $\mathrm{Co}^{2+}$ Loading of AuLA-GSH}

Hypoxia and inflammatory responses usually cause changes in microenvironment $\mathrm{pH}$ from neutral to acidic. This characteristic of lesions provides an intrinsic basis for a $\mathrm{pH}-$ responsive DDS design. ${ }^{37}$ Buffer solutions with a $\mathrm{pH} 7.4$ and 6.0 PBS were introduced to mimic normal physiological and pathological environments, respectively. Abundant lone pair electrons of $-\mathrm{SH}$ and $-\mathrm{COOH}$ residues on the surface of AuLA-GSH could easily coordinate with transition metal ions. $^{38,39}$ which enabled AuLA-GSH to be an ideal metal ion carrier. By co-incubation with $\mathrm{Co}^{2+}, \mathrm{Ni}^{2+}$ or $\mathrm{Cu}^{2+}$ under a $\mathrm{pH}$ of 7.4, the fluorescence intensities of AuLA-GSH $-x$ ( $x$ represents $\mathrm{Co}$ or $\mathrm{Ni}$ or $\mathrm{Cu})$ at the maximum emission wavelength $(705 \mathrm{~nm})$ were reduced by $31.4 \%, 52.8 \%$ and $89.4 \%$, respectively (Figure $3 \mathrm{~A}$ ). This was attributed to the ion-induced coordinate self-assembly of AuLA-GSH. ${ }^{40,41}$ When changing the $\mathrm{pH}$ values of these mixtures from 7.4 to 6.0, the fluorescence intensities of AuLA-GSH-Co and AuLA-GSH-Ni recovered by $\sim 30 \%$, while the fluorescence intensity of AuLA-GSH-Cu did not change (Figure 3B, S3). This was due to the fact that the strength of coordination bonds between $\mathrm{Cu}^{2+}$ ions and residues in AuLA-GSH was more robust than those of $\mathrm{Co}^{2+}$ and $\mathrm{Ni}^{2+}$ ions, which would not be influenced by $\mathrm{pH}$. The fluorescence switch performance of AuLA-GSH-Co and AuLA-GSH-Ni could be generated by tuning $\mathrm{pH}$ values between 7.4 and 6.0, which meant that $\mathrm{Co}$ and $\mathrm{Ni}$ ions would be released in an acidic environment. This is a fundamental characteristic for AuLA-GSH to be a controllable drug carrier.

Cobalt has been reported as a promising drug for kidney fibrosis. $^{26}$ Thus, AuLA-GSH-Co was further studied as a drug delivery system targeting renal fibrosis. As shown in Figure 3C, the hydrodynamic size of AuLA-GSH-Co 
A

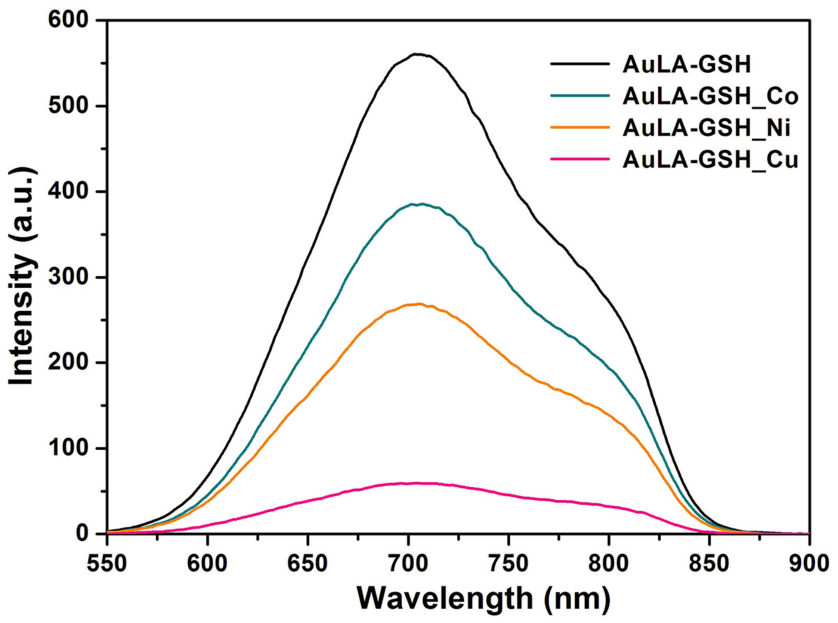

C

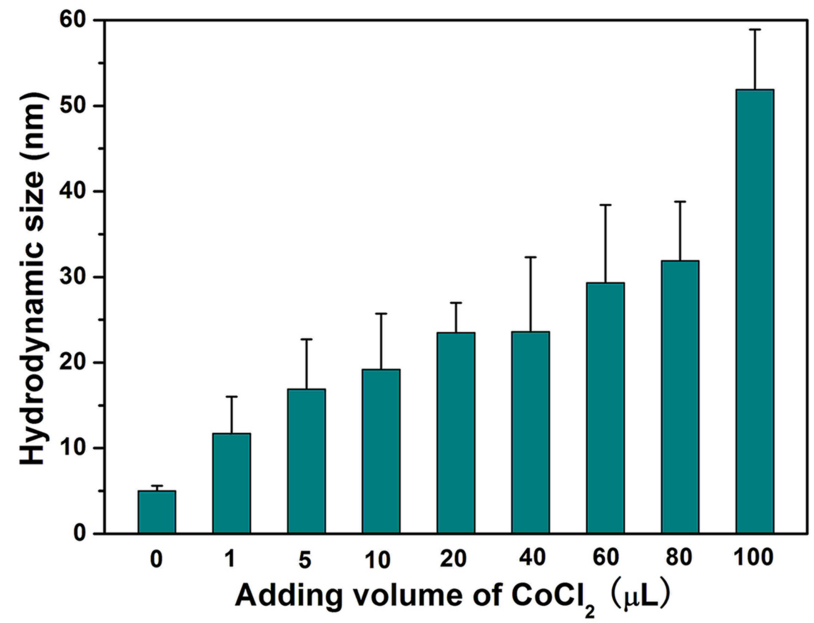

E

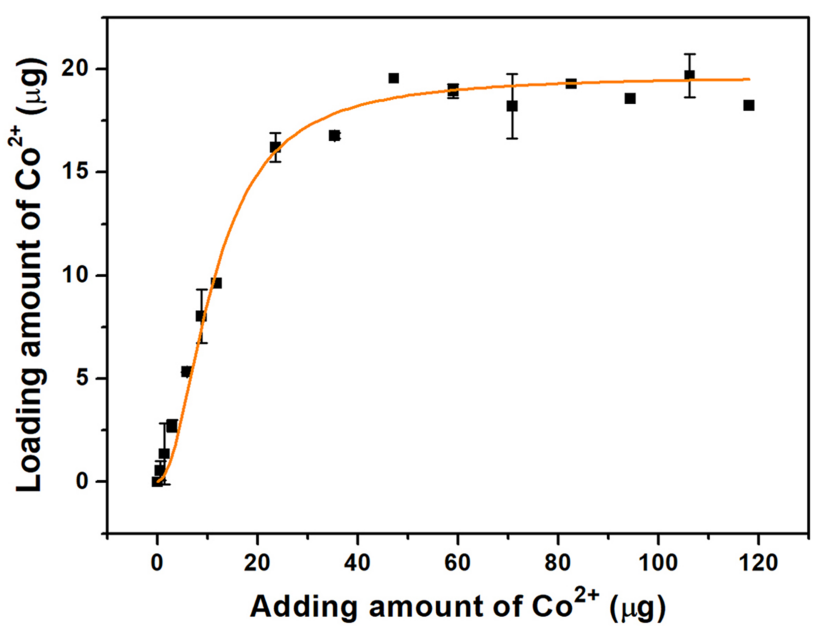

B

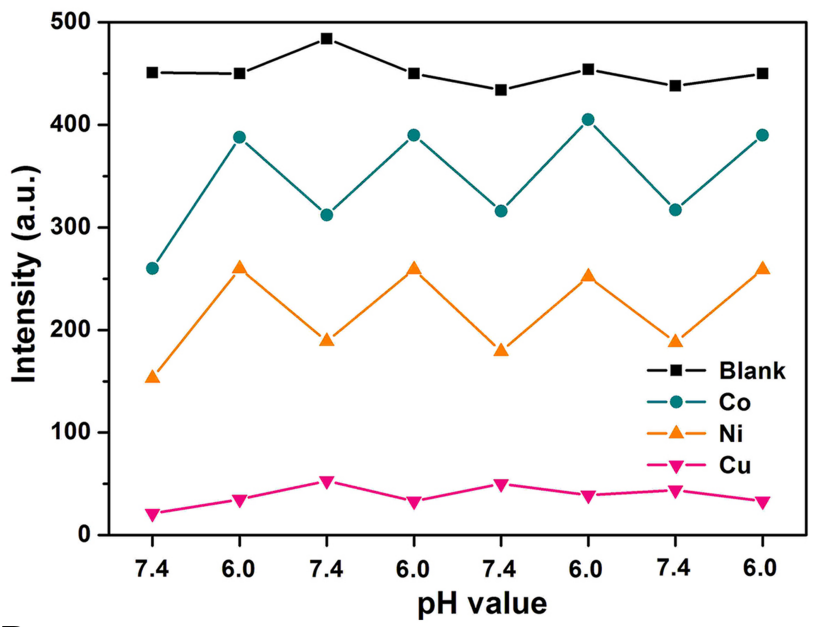

D

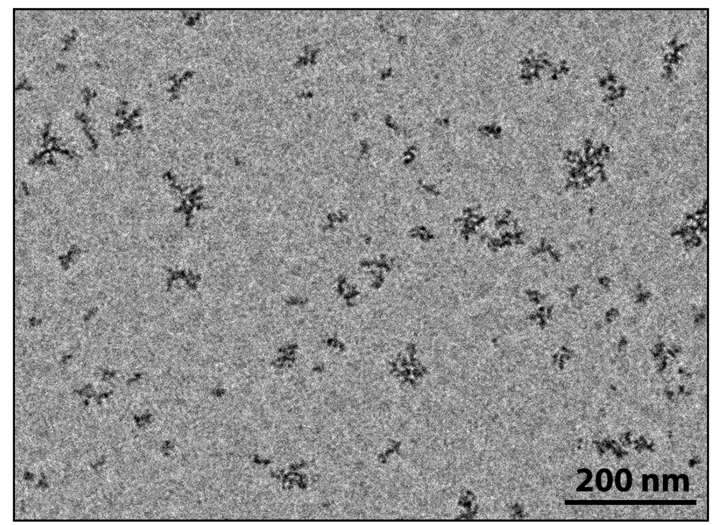

F

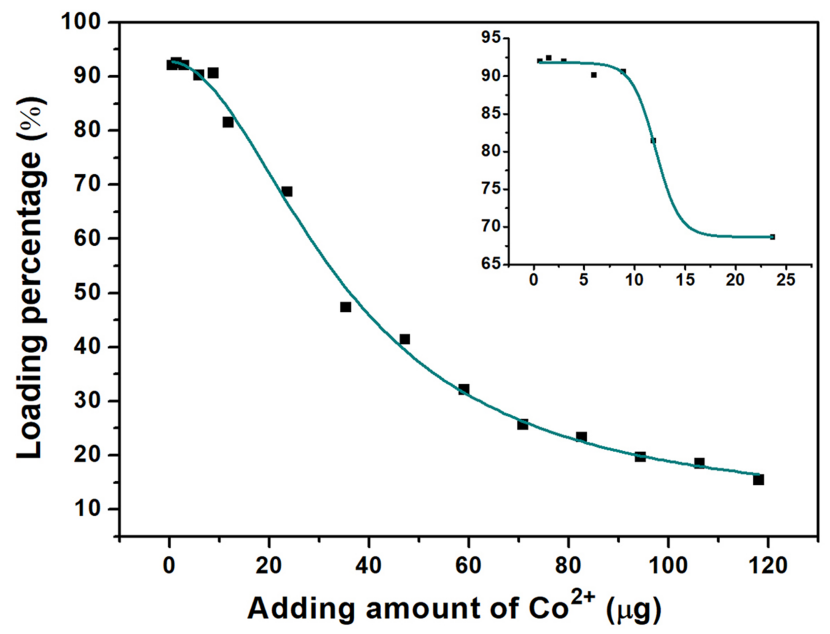

Figure 3 Fluorescence switches and drug loading measurements. (A) Fluorescence emission spectra of AuLA-GSH incubated with $\mathrm{Co}^{2+}$, Ni ${ }^{2+}$ or $\mathrm{Cu}^{2+}$ ions, respectively. $(\mathbf{B})$ The fluorescence intensities at $705 \mathrm{~nm}$ of AuLA-GSH or AuLA-GSH-Co/Ni/Cu under pH 7.4 or 6.0. (C) Hydrodynamic sizes of I00 $\mu \mathrm{L}$ AuLA-GSH incubated with different volumes $(0-100 \mu \mathrm{L})$ of $10 \mathrm{mM} \mathrm{CoCl} 2$ aqueous solution and PBS $(100-0 \mu \mathrm{L})$ for $2 \mathrm{~h}$ and (D) TEM image of AuLA-GSH-Co under neutral conditions. (E) Loading amount and correlated (F) loading percentage curves of $\mathrm{Co}^{2+}$ on AuLA-GSH-Co. 
increased when the added amount of $\mathrm{Co}^{2+}$ increased. At the same time, the fluorescence intensity of AuLA-GSH diminished gradually along with increasing $\mathrm{Co}^{2+}$ volume (Figure S4). AuLA-GSH-Co assemblies were composed of several nanoparticles with $\mathrm{Co}^{2+}$ ions entrapped (Figure 3D). The loading amount of $\mathrm{Co}^{2+}$ in AuLA-GSH-Co samples was determined using ICP-MS (Figure $3 \mathrm{E}$ and F). When the amount added was lower than $10 \mu \mathrm{g}$, the loading percentage of $\mathrm{Co}^{2+}$ was higher than $80 \%$, indicating that most $\mathrm{Co}^{2+}$ was entrapped in the DDS. The loading percentage gradually decreased when the amount of $\mathrm{Co}^{2+}$ was increased, indicating a saturation state of AuLA-GSH in loading $\mathrm{Co}^{2+}$. Thus, the most effective loading point of $\mathrm{Co}^{2+}$ was $10 \mu \mathrm{L}$ adding volume.

\section{Cellular Toxicity and Uptake Assays}

The proximal tubule NRK-52E and renal fibroblast NRK49F cell lines were introduced to evaluate cellular toxicity of AuLA-GSH. Cells were incubated with different concentrations of AuLA-GSH $(0-4000 \mu \mathrm{M})$ and $\mathrm{CoCl}_{2}(0-40$ $\mu \mathrm{M})$. CCK-8 results revealed that cell viabilities cocultured with AuLA-GSH were greater than $90 \%$ at different time points $(6,12,24 \mathrm{~h})$, indicating that AuLA-GSH had good biocompatibility (Figure $4 \mathrm{~A}$ and B), which laid a solid foundation for its biomedical application. In contrast, $\mathrm{CoCl}_{2}$ showed considerable cytotoxicity at high concentrations (Figure S5). The uptake efficiencies of AuLA and AuLA-GSH in NRK-52E cells were next investigated. As shown in Figure 4C and D, the red fluorescence was much stronger in cells incubated with AuLA-GSH compared to cells incubated with AuLA. The fluorescence intensity of AuLA-GSH incubated cells was 1.6 times more than AuLA incubated cells. This may be due to the enhanced fluorescence of AuLA-GSH and the specific targeting ability of GSH to proximal tubules. Cell slices observed by TEM confirmed that AuLA-GSH could be taken up through endocytosis after a period of co-culturing (Figure S6).

To further quantify cellular uptake of $\mathrm{Co}^{2+}$ cell samples incubated with $\mathrm{CoCl}_{2}$ or AuLA-GSH-Co for 0-48 $\mathrm{h}$ were digested and measured by ICP-MS (Figure 4E). The concentrations of $\mathrm{Co}^{2+}$ in AuLA-GSH-Co incubated cells were much higher than in $\mathrm{CoCl}_{2}$ incubated cells within $1 \mathrm{~h}$, which may be attributed to the nanoencapsulation of $\mathrm{Co}^{2+}$ ions in AuLA-GSH-Co, enhancing endocytosis and slowing exocytosis. This feature allows AuLA-GSH as an ideal candidate for $\mathrm{Co}^{2+}$ delivery.
To observe the distribution of AuLA-GSH in cells, the two specific fluorescent tracer molecules LAMP-1-FITC (green fluorescence) and DAPI (blue fluorescence) were introduced to label lysosomes and nuclei, respectively. ${ }^{42}$ Co-location imaging results showed that the position of AuLA-GSH (red fluorescence) mostly overlapped with lysosomes (green fluorescence), while red fluorescence was almost absent in the nucleus (blue fluorescence) (Figure S7). This indicated that AuLA-GSH was mostly present in lysosomes.

\section{Targeting AuLA-GSH to the Kidney}

To verify the kidney-targeting ability of AuLA-GSH, nude mice were injected with PBS, AuLA or AuLA-GSH intraperitoneally. AuLA and AuLA-GSH showed red fluorescence under the in vivo imaging system (Figure S8). After injecting, mice were sacrificed at different time points to harvest major organs (heart, liver, spleen, lung, kidneys, brain, small intestine and muscle) and observed using the imaging system. Organs collected from mice injected with PBS served as controls and showed weak autofluorescence (Figure S9). AuLA-GSH injected mice exhibited strong fluorescence in the kidneys for at least $12 \mathrm{~h}$, whereas AuLA injected mice showed weak fluorescence intensity in the kidneys at $6 \mathrm{~h}$ p.i. (Figure 5A). Most of the AuLAGSHs accumulated in the kidney and bladder at $1 \mathrm{~h}$ p.i., indicated that AuLA-GSH could specifically target the kidney and be excreted in urine (Figure 5B). It is well known that the liver is the largest RES organ and nonspecific accumulation of nanoparticles are most likely to occur in this organ. ${ }^{43}$ Here, an intensity contrast index $(C I)^{44}$ was introduced to visually describe the kidneytargeting efficiency of nanoparticles, which represented the contrast intensity of kidneys to the liver and was calculated as follows:

$$
C I=\frac{\text { Fluorescence intensity of kidneys }}{\text { Fluorescence intensity of liver }}-1
$$

When the CI value was positive, it indicated that the fluorescence intensity of the kidneys was stronger than the liver. Otherwise, the florescence intensity of the liver was stronger than the kidneys. As shown in Figure 5C, CI values remained positive within $6 \mathrm{~h}$ p.i. for AuLA-GSH injected mice. In contrast, CI values for AuLA injected mice were almost all negative. This result indicated a remarkable advantage of AuLA-GSH in kidney targeting. 
A

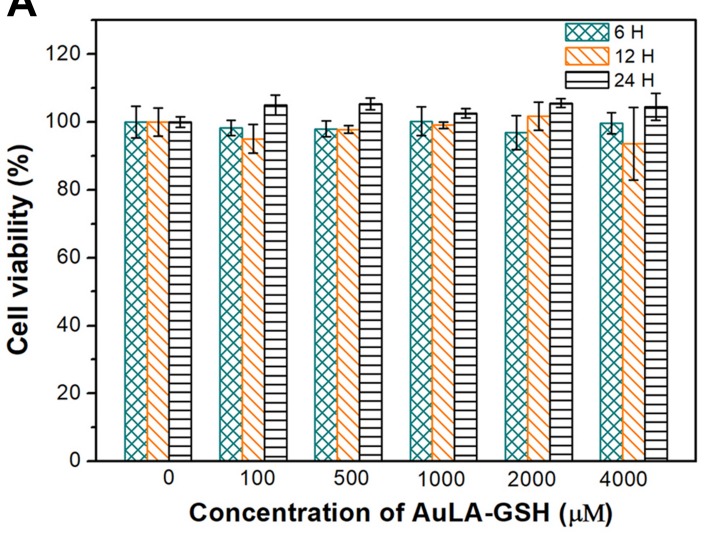

B

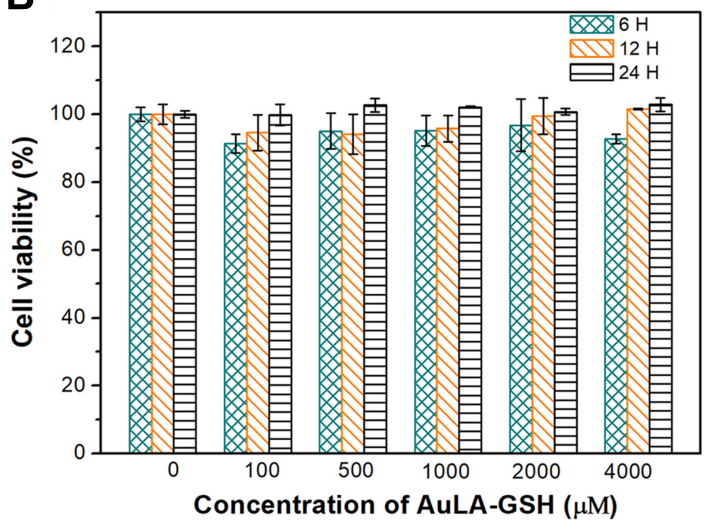

C

Control
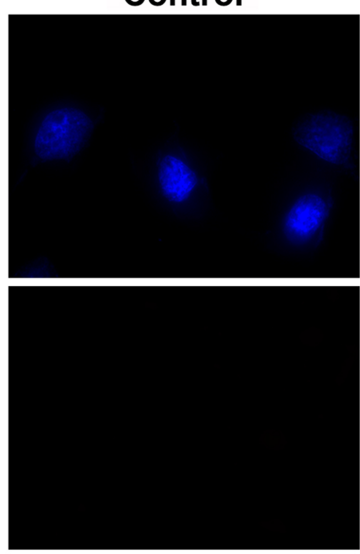

TRITC

Merge

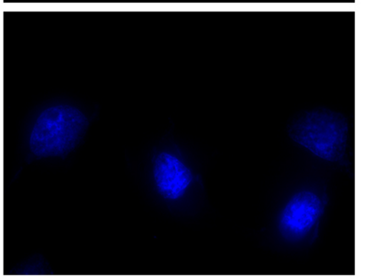

D

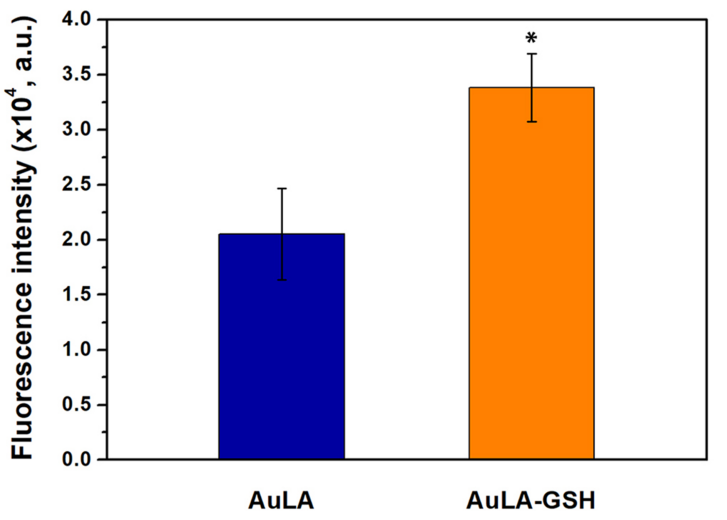

AuLA-GSH
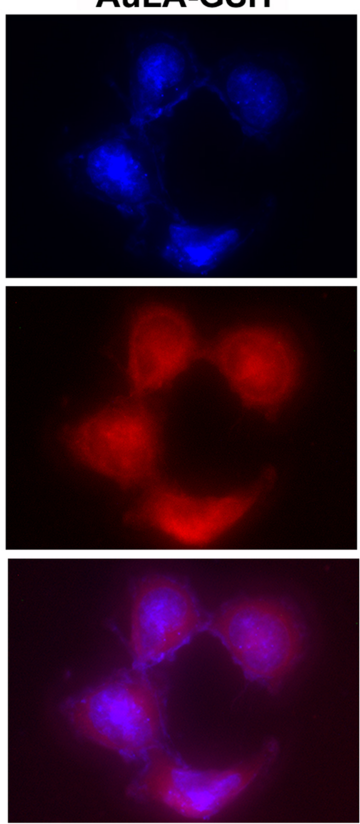

E

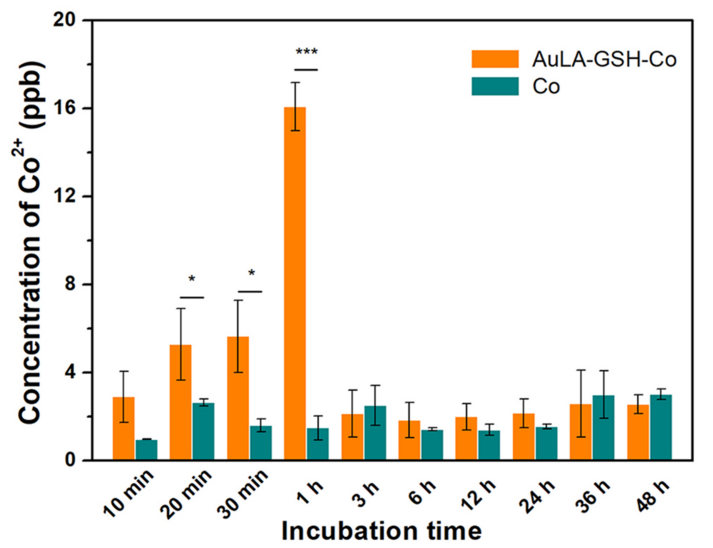

Figure 4 Cytotoxicity and cellular uptake analysis. Cell viability of (A) NRK-52E and (B) NRK-49F cell lines treated with AuLA-GSH for 6, 12 or 24 h. (C) Fluorescence images of NRK-52E incubated with PBS, AuLA or AuLA-GSH for 3 h. (D) Corresponding fluorescence intensities of nanoparticles in cells. (E) Cellular uptake of Co ${ }^{2+}$ in NRK-52E cells incubated with AuLA-GSH-Co or $\mathrm{CoCl}_{2}$ within $48 \mathrm{~h}$. Data are expressed as mean $\pm \mathrm{SD}, \mathrm{n} \geq 3$. ${ }^{*} \mathrm{p}<0.05$, ***p $<0.00 \mathrm{l}$. 
A

A $1 \mathrm{~h}$
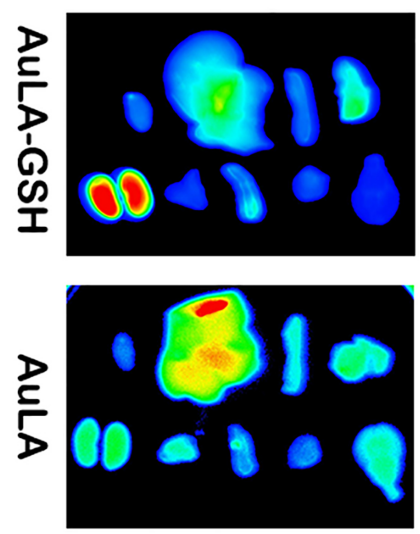

B

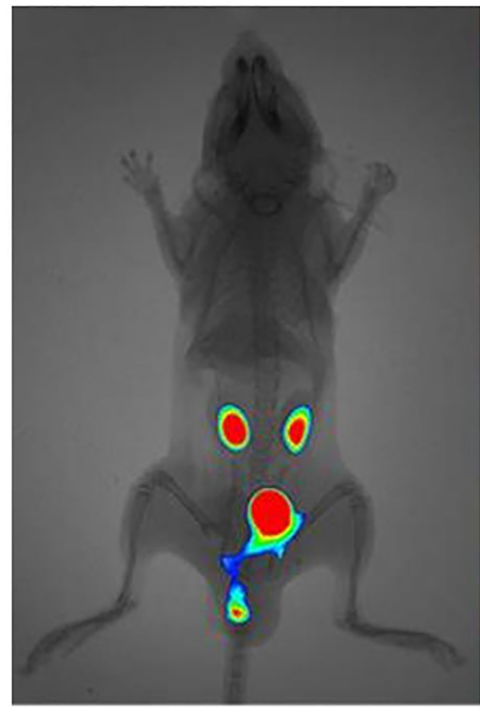

$3 \mathrm{~h}$
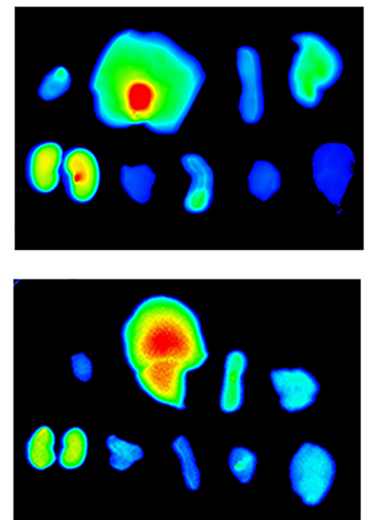

$6 \mathrm{~h}$
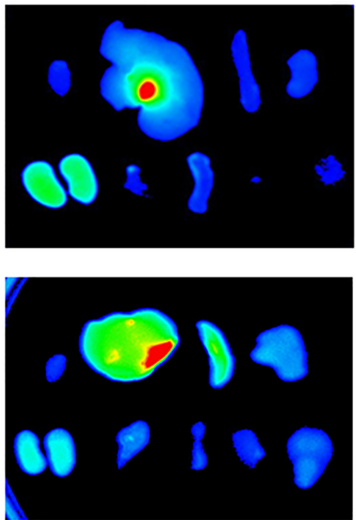

$12 \mathrm{~h}$
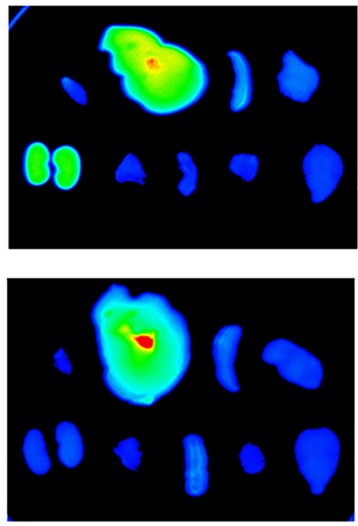

C

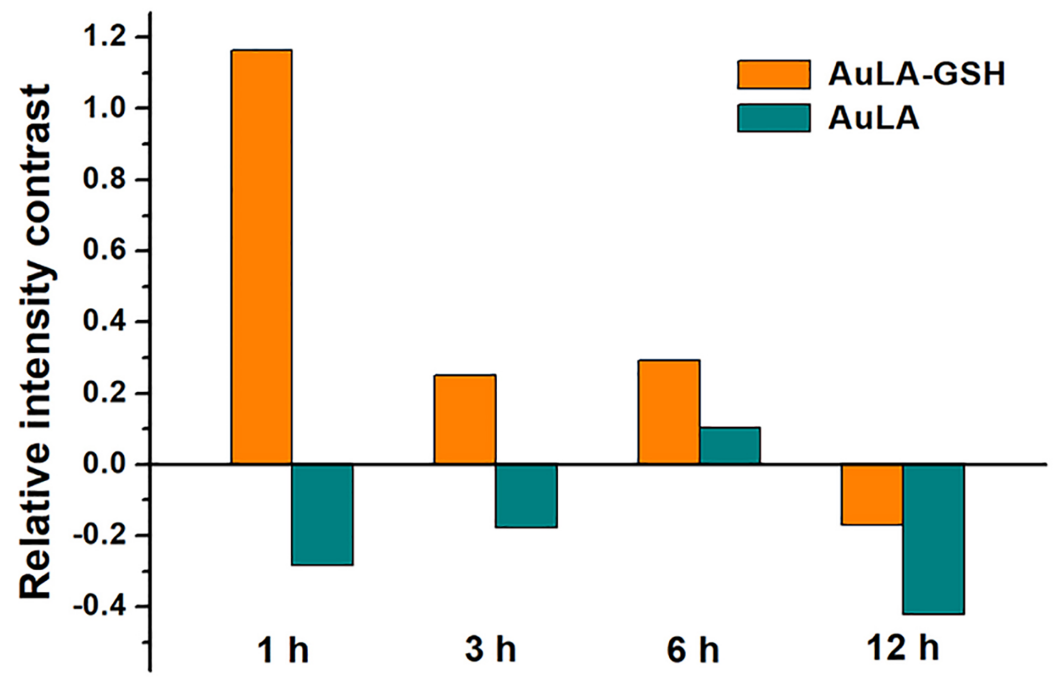

D DAPI

AQP-1

AuLA-GSH
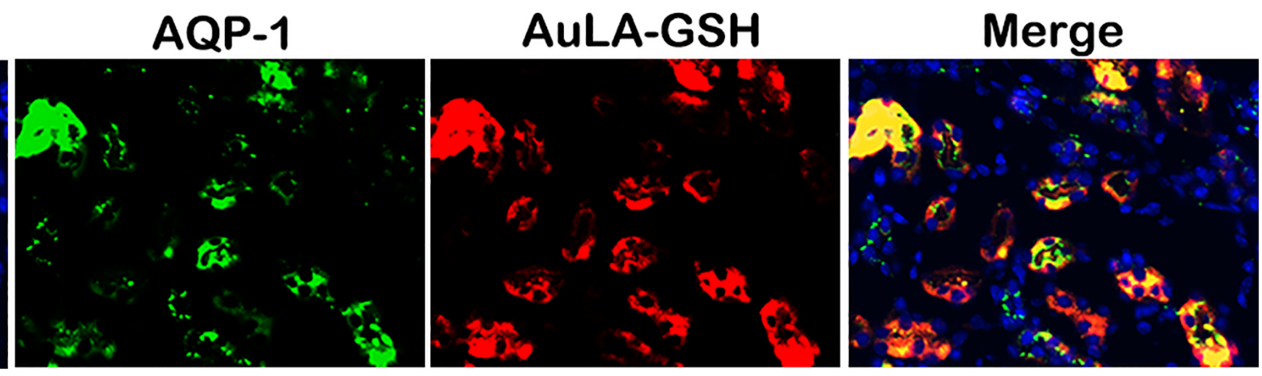

Figure 5 In vivo and ex vivo bio-distribution of AuLA and AuLA-GSH. (A) Ex vivo fluorescent images of major organs collected from mice injected with AuLA or AuLAGSH at different time intervals (I, 6 and $12 \mathrm{~h}$ ) (I-9, heart, liver, spleen, lung, kidneys, thymus, small intestine, muscle, brain). (B) In vivo fluorescence distribution of nude mice after I h AuLA-GSH injection. (C) Relative contrast indexes representing contrast fluorescence intensity of kidneys to liver were calculated at different time points. (D) Co-localization images of AQP-I (green), nucleus (blue) and AuLA-GSH (red) in kidney sections.

To further verify the targeting location of AuLA-GSH, kidney frozen sections were collected and stained with AQP-1, which mainly was expressed in the epithelial cell membrane of proximal tubules but not in the glomerulus or other types of tubules. ${ }^{45}$ Figure 5D reveals that the position of AuLA-GSH (red fluorescence) and AQP-1 (green fluorescence) almost completely overlapped and the fluorescence of AuLA-GSH outlined the shape of renal tubules. This indicated 
A

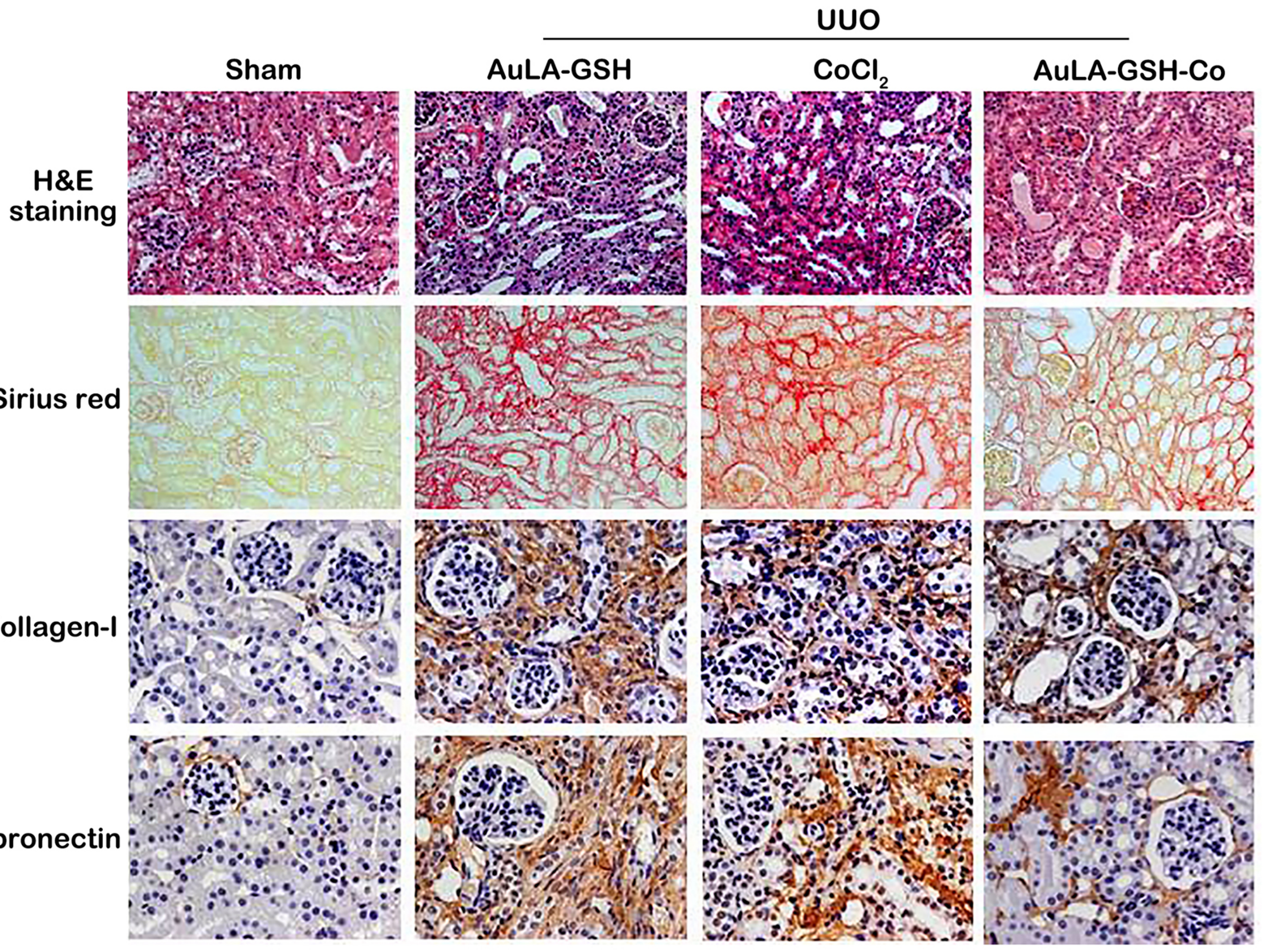

B

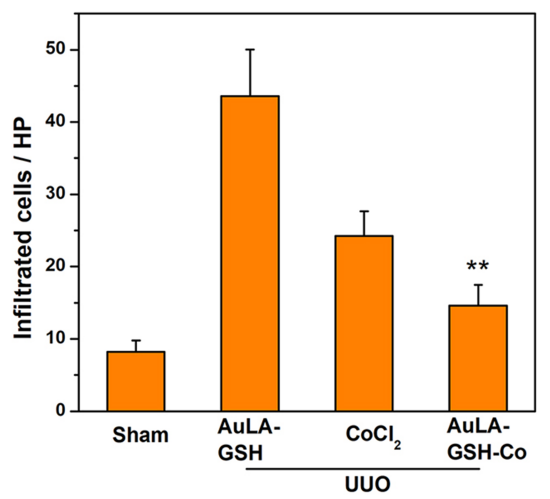

C

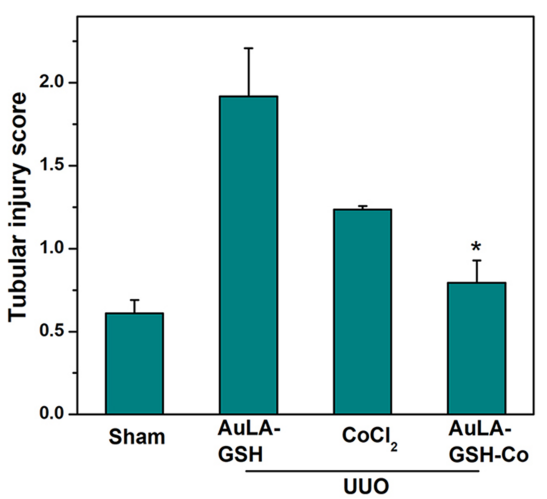

D

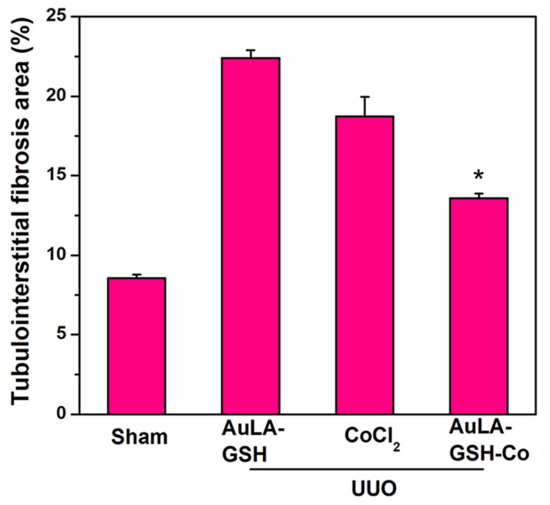

Figure 6 Histology and pathology analysis of kidneys in different treatment groups. (A) Histological sections of kidneys collected from different treatment groups stained with H\&E, Sirius red and immunohistochemical staining of collagen-I and fibronectin. (B) Quantitative assessment of tubular injury score, (C) infiltrated cells and (D) tubulointerstitial fibrosis area in different treatment groups. Data are expressed as mean $\pm \mathrm{SD}, \mathrm{n}=5 .{ }^{*}<0.05$ versus $\mathrm{UUO}+\mathrm{CoCl} 2$ group. $* * \mathrm{p}<0.0 \mathrm{I}$ versus $\mathrm{UUO}+\mathrm{CoCl} \mathrm{C}_{2}$ group.

that AuLA-GSH specifically targeted proximal tubular cells, which could be the internal reason for the significant renal targeting of AuLA-GSH.

\section{In vivo Antifibrosis Efficacy}

Sham mice and UUO mice injected with AuLA-GSH, $\mathrm{CoCl}_{2}$ or AuLA-GSH-Co for 7 days with a $\mathrm{Co}^{2+}$ dose of $5 \mathrm{mg} / \mathrm{kg}$ mouse were weighed every day. All mice were sacrificed on the $7^{\text {th }}$ day p.i., and main organs including the heart, liver, spleen, lung and kidneys were collected for histological staining. H\&E staining of the heart, liver, spleen and lung for each mouse indicated that all interventions did not harm normal organs (Figure S10). Compared to the Sham group, the kidneys of UUO mice treated with AuLA-GSH showed 
apparent tubular cell damage accompanied by tubular expansion, inflammatory cell infiltration and severe interstitial fibrosis (Figure 6A). Moreover, collagen-I and fibronectin staining revealed that the kidneys of UUO mice showed obvious collagen deposition and fibrosis. The degree of kidney damage in UUO mice treated with $\mathrm{CoCl}_{2}$ was slightly relieved and the deformation of renal tubules and the lumen was smaller than what was observed in the AuLA-GSH group. Surprisingly, kidney morphology of UUO mice treated with AuLA-GSH-Co was significantly restored, the number of inflammatory cells was reduced and the tubular shape was similar to what was observed in the Sham group. The Masson staining results showed the same trend (Figure S11).

Figure 6B-D includes a semi-quantitative analysis of tubular damage index, the number of infiltrated inflammatory cells and interstitial fibrosis area in the kidney for each mouse group. Inflammatory cells reduced from $80 \%$
A
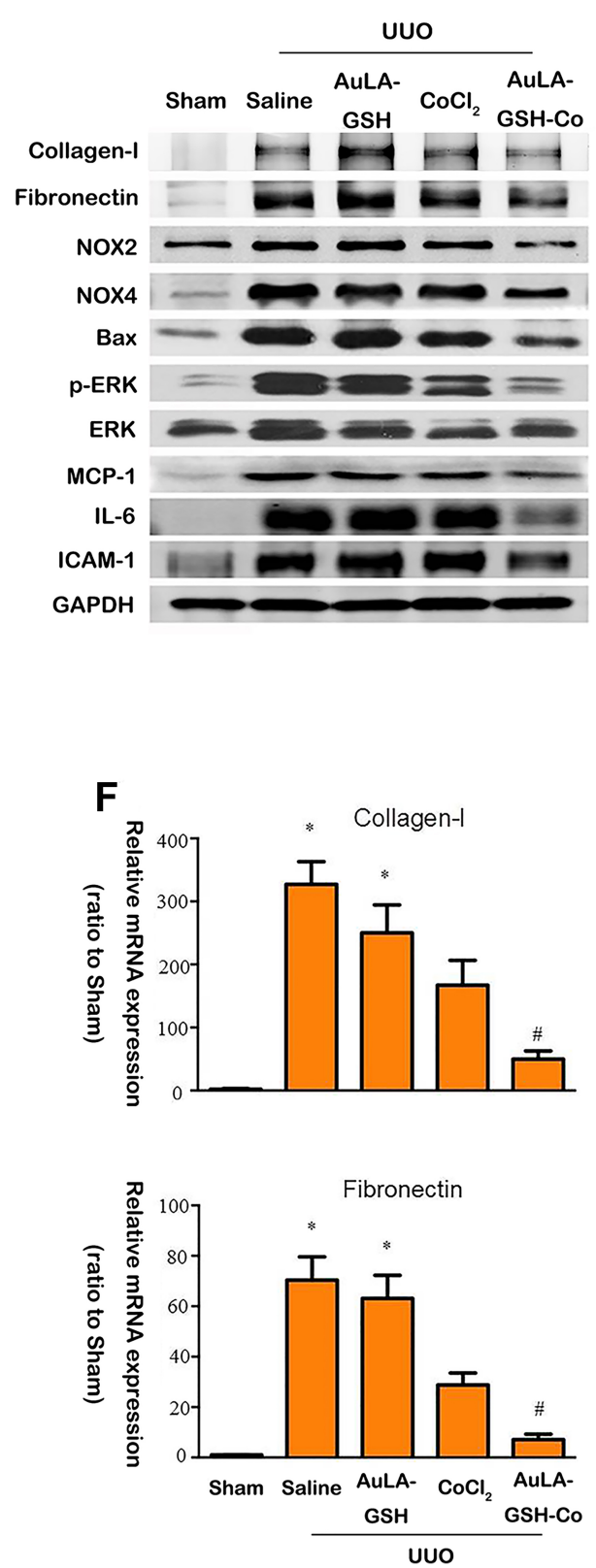

B
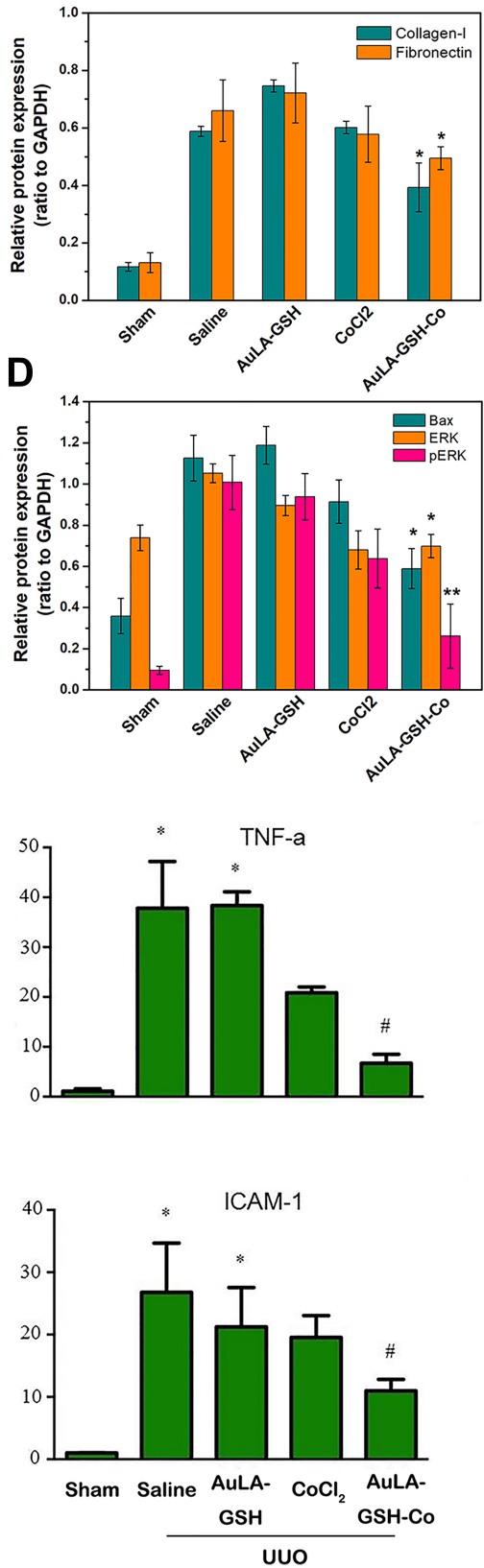

C
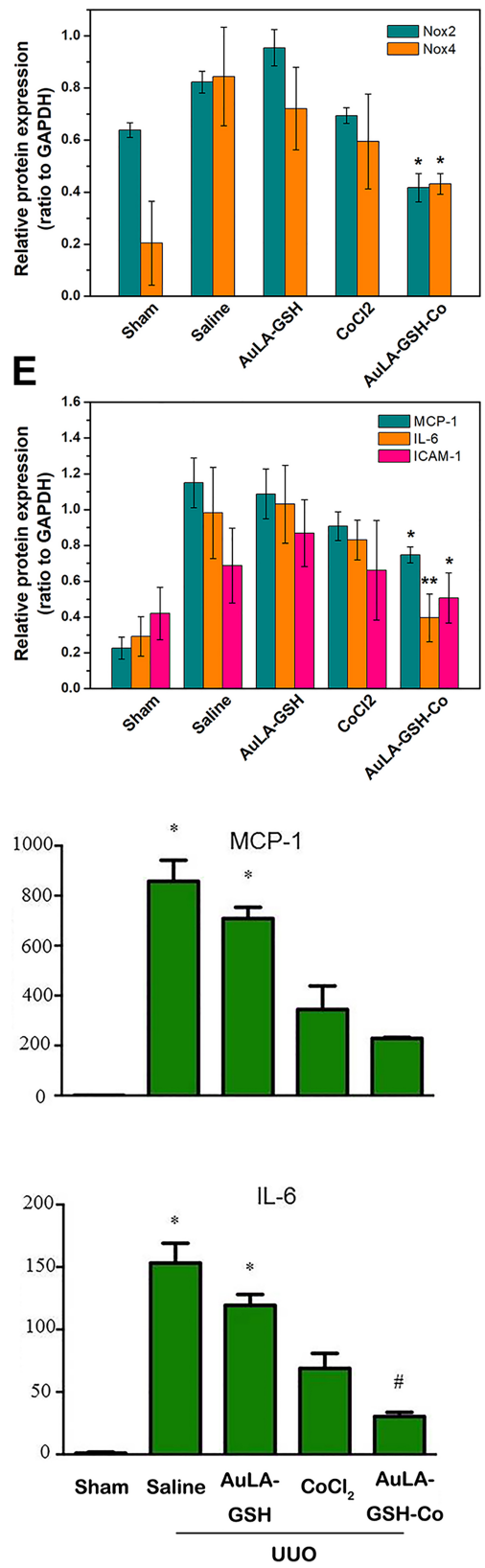

Figure 7 (A) Representative protein expression of collagen-I and fibronectin (renal fibrosis), Nox2 and Nox4 (oxidative stress), Bax, p-ERK and ERK (pro-apoptosis), MCPI, IL-6 and ICAM-I (pro-inflammation). (B-E) Quantitative data for protein expression levels. (F) mRNA expression levels of collagen-I, fibronectin, MCP-I, TNF- $\alpha$, ICAM-I and IL-6. Data are expressed as mean $\pm S D, n=5$. ${ }^{*} p<0.05$ versus Sham group, ${ }^{* *} p<0.01$ versus Sham group, $\# p<0.05$ versus UUO+CoCl 2 group. 
to $50 \%$ and $30 \%$ in $\mathrm{CoCl}_{2}$ and AuLA-GSH-Co treated mice, respectively. Furthermore, the ratio of interstitial fibrosis was decreased to $16.2 \%$ in the AuLA-GSH-Co group, while ratios were $40.5 \%$ and $31.3 \%$ in the AuLAGSH and $\mathrm{CoCl}_{2}$ groups, respectively. Their results indicated that AuLA-GSH-Co played a prominent role in maintaining tissue morphology of the damaged kidney and reducing infiltration.

\section{Molecular Biology Assays Confirming Anti-Fibrosis Efficiency}

A variety of fibro-related proteins in the kidney were analyzed by Western blotting. As shown in Figure 7A and B, AuLA-GSH-Co significantly down-regulated collagen-I and fibronectin expression levels by 2.5 and 1.4-fold lower, respectively, than what was observed in the saline group. The expression levels of other representative proteins including Nox2, Nox4, Bax, p-ERK and ERK, were also dramatically reduced in the AuLA-GSH-Co group (Figure 7C-E).

To further confirm anti-fibrosis efficiency, real-time PCR testing was used. Figure 7F reveals that fibrorelated mRNA expression levels of collagen-I, fibronectin and IL-6 were significantly reduced in the AuLA-GSH-Co group compared to the saline and $\mathrm{CoCl}_{2}$ groups, which was consistent with Western blotting results. These findings demonstrated that AuLA-GSH-Co has the ability to reduce extracellular matrix deposition and act as an ideal strategy for renal fibrosis therapy.

\section{Conclusion}

Here, we have prepared GSH-modified gold nanoparticles, AuLA-GSHs containing enhanced fluorescence properties and remarkable renal targeting ability. Plentiful lone pair electrons on the surface of AuLA-GSHs possessed them with excellent metal coordination ability, which was beneficial to load and deliver $\mathrm{Co}^{2+}$ as a potential anti-fibrosis drug. In vitro and in vivo experiments revealed that the AuLA-GSH significantly improved kidney targeting compared to AuLA. In addition, self-assembled AuLA-GSH-Co showed a significant advantage in anti-fibrosis efficiency compared to free $\mathrm{Co}^{2+}$ With these attractive properties, AuLA-GSH-Co is a promising drug delivery platform for renal fibrosis and other diseases.

\section{Abbreviations}

AuNPs, gold nanoparticles; GSH, glutathione; CKD, chronic kidney disease; HIF, hypoxia-inducible factor; RES, reticuloendothelial system; UUO, unilateral ureteral obstruction; OD, optical density; DAPI, phenylindoles; CI, contrast index.

\section{Funding}

This work was supported by the Key project of Guangdong Natural Science Foundation (2018B0303110002), Shenzhen Sanming Project (SZSM20161204) and Shenzhen Science, Technology Innovation Commission Project (GJHZ 20180754917, ZDSYS201909020 92855097) and China postdoctoral science foundation general program (2018M643135). The authors have no other relevant affiliations or financial involvement with any organizations or entities with a financial interest in or financial conflict with the subject matter or materials discussed in the manuscript.

\section{Disclosure}

The authors report no conflicts of interest in this work.

\section{References}

1. Kim D, Shin K, Kwon SG, Hyeon T. Synthesis and biomedical applications of multifunctional nanoparticles. Adv Mater. 2018;30 (49):e1802309. doi:10.1002/adma.201802309

2. Sun T, Zhang YS, Pang B, et al. Engineered nanoparticles for drug delivery in cancer therapy. Angew Chem Int Ed Engl. 2014;53 (46):12320-12364. doi:10.1002/anie.201403036

3. Shahriari M, Hemmati S, Zangeneh A, et al. Decoration of silver nanoparticles on multi-walled carbon nanotubes: investigation of its anti-acute leukemia property against acute myeloid leukemia and acute T cell leukemia. Appl Organometal Chem. 2020;34:e5476. doi:10.1002/aoc.5476

4. Pedrosa P, Vinhas R, Fernandes A, et al. Gold nanotheranostics: proof-of-concept or clinical tool? Nanomaterials. 2015;5 (4):1853-1879. doi:10.3390/nano5041853

5. Panyala NR, Peña-Méndez EM, Havel J. Gold and nano-gold in medicine: overview, toxicology and perspectives. J Appl Biomed. 2009;7(2):75-91. doi:10.32725/jab.2009.008

6. Sztandera K, Gorzkiewicz M, Klajnert-Maculewicz B. Gold nanoparticles in cancer treatment. Mol Pharm. 2019;16(1):1-23. doi:10.1021/ acs.molpharmaceut. $8 \mathrm{~b} 00810$

7. Dlugosz O, Szostak K, Staron A, et al. Methods for reducing the toxicity of metal and metal oxide NPs as biomedicine. Materials. 2020;13(2):279. doi:10.3390/ma13020279

8. Her S, Jaffray DA, Allen C. Gold nanoparticles for applications in cancer radiotherapy: mechanisms and recent advancements. $A d v$ Drug Deliv Rev. 2017;109:84-101. doi:10.1016/j.addr.2015.12.012

9. Ahmeda A, Zangeneh MM. Novel green synthesis of Boswellia serrata leaf aqueous extract conjugated gold nanoparticles with excellent anti-acute myeloid leukemia property in comparison to mitoxantrone in a leukemic mice model: introducing a new chemotherapeutic drug. Appl Organometal Chem. 2020;34:e5344. doi:10.1002/aoc.5344

10. Cheng L, Jiang D, Kamkaew A, et al. Renal-clearable PEGylated porphyrin nanoparticles for image-guided photodynamic cancer therapy. $A d v$ Funct Mater. 2017;27(34):1702928. doi:10.1002/adfm.201702928

11. Shiao Y-S, Chiu -H-H, Wu P-H, et al. Aptamer-functionalized gold nanoparticles as photoresponsive nanoplatform for co-drug delivery. ACS Appl Mater Interfaces. 2014;6(24):21832-21841. doi:10.1021/ am5026243 
12. Mahalunkar S, Yadav AS, Gorain M, et al. Functional design of $\mathrm{pH}$-responsive folate-targeted polymer-coated gold nanoparticles for drug delivery and in vivo therapy in breast cancer. Int $J$ Nanomed. 2019;14:8285-8302. doi:10.2147/IJN.S215142

13. Zhou C, Hao G, Thomas P, et al. Near-infrared emitting radioactive gold nanoparticles with molecular pharmacokinetics. Angew Chem Int Ed Engl. 2012;51(40):10118-10122. doi:10.1002/anie.201203031

14. Vinluan RD, Liu J, Zhou C, et al. Glutathione-coated luminescent gold nanoparticles: a surface ligand for minimizing serum protein adsorption. ACS Appl Mater Interfaces. 2014;6(15):11829-11833. doi:10.1021/am5031374

15. Chen W, Tu X, Guo X. Fluorescent gold nanoparticles-based fluorescence sensor for $\mathrm{Cu}^{2+}$ ions. Chem Commun. 2009;(13):1736-1738. doi:10.1039/b820145e

16. Fu R, Li J, Yang W. Aggregation of glutathione-functionalized Au nanoparticles induced by $\mathrm{Ni}^{2+}$ ions. J Nanopart Res. 2012;14(6):929. doi:10.1007/s11051-012-0929-y

17. Friedman SL, Sheppard D, Duffield JS, et al. Therapy for fibrotic diseases: nearing the starting line. Sci Transl Med. 2013;5(167):1-17. doi:10.1126/scitranslmed.3004700

18. Ovadya Y, Krizhanovsky V. A new Twist in kidney fibrosis. Nat Med. 2015;21(9):975-977. doi:10.1038/nm.3938

19. Declèves AE, Sharma K. Novel targets of antifibrotic and anti-inflammatory treatment in CKD. Nat Rev Nephrol. 2014;10 (5):257-267. doi:10.1038/nrneph.2014.31

20. Geng XR, Zhang MB, Lai XD, et al. Small-sized cationic miRi-PCNPs selectively target the kidneys for high-efficiency antifibrosis treatment. Adv Healthcare Mater. 2018;7(21):1800558. doi:10.1002/adhm. 201800558

21. Bideak A, Blaut A, Hoppe JM, et al. The atypical chemokine receptor 2 limits renal inflammation and fibrosis in murine progressive immune complex glomerulonephritis. Kidney Int. 2018;93 (4):826-841. doi:10.1016/j.kint.2017.11.013

22. Zhang MY, Yan ZB, Bu LL, et al. Rapeseed protein-derived antioxidant peptide RAP alleviates renal fibrosis through MAPK/NF-kappa B signaling pathways in diabetic nephropathy. Drug Des Dev Ther. 2018;12:1255-1268. doi:10.2147/DDDT.S162288

23. Qiao H, Sun M, Su Z, et al. Kidney-specific drug delivery system for renal fibrosis based on coordination-driven assembly of catechol-derived chitosan. Biomaterials. 2014;35(25):7157-7171. doi:10.1016/j.biomaterials.2014.04.106

24. Tan LS, Lai XD, Zhang MB, et al. A stimuli-responsive drug release nanoplatform for kidney-specific anti-fibrosis treatment. Biomater Sci. 2019;7(4):1554-1564. doi:10.1039/C8BM01297K

25. Myllyharju J. Prolyl 4-hydroxylases, the key enzymes of collagen biosynthesis. Matrix Biol. 2003;22(1):15-24. doi:10.1016/s0945053x(03)00006-4

26. Nordquist L, Friederich-Persson M, Fasching A, et al. Activation of hypoxia-inducible factors prevents diabetic nephropathy. $J$ Am Soc Nephrol. 2014;26(2):328-338. doi:10.1681/asn.2013090990

27. Tanaka T, Kojima I, Ohse T, et al. Cobalt promotes angiogenesis via hypoxia-inducible factor and protects tubulointerstitium in the remnant kidney model. Lab Invest. 2005;85(10):1292-1307. doi:10.1038/ labinvest. 3700328

28. Shang L, Azadfar N, Stockmar F, et al. One-pot synthesis of near-infrared fluorescent gold clusters for cellular fluorescence lifetime imaging. Small. 2011;7(18):2614-2620. doi:10.1002/ sml1.201100746
29. Zhou C, Sun C, Yu MX, et al. Luminescent gold nanoparticles with mixed valence states generated from dissociation of polymeric Au (I) thiolates. J Phys Chem C. 2010;114(17):7727-7732. doi:10.1021/ jp9122584

30. Gomes LC, Di Benedetto G, Scorrano L. During autophagy mitochondria elongate, are spared from degradation and sustain cell viability. Nat Cell Biol. 2011;13(5):589-598. doi:10.1038/ncb2220

31. Babickova J, Klinkhammer BM, Buhl EM, et al. Regardless of etiology, progressive renal disease causes ultrastructural and functional alterations of peritubular capillaries. Kidney Int. 2017;91 (1):70-85. doi:10.1016/j.kint.2016.07.038

32. Oltval ZN, Milliman CL, Korsmeyer SJ. BCL-2 heterodimerizes In-vivo with a conserved homolog, BAX, that accelerates programmed cell-death. Cell. 1993;74(4):609-619. doi:10.1016/00928674(93)90509-O

33. Bruno S, Grange C, Deregibus MC, et al. Mesenchymal stem cell-derived microvesicles protect against acute tubular injury. $\mathrm{J} \mathrm{Am}$ Soc Nephrol. 2009;20(5):1053-1067. doi:10.1681/ASN.2008070798

34. Khan S, Sharma A, Ghoshal S, et al. Small molecular organic nanocrystals resemble carbon nanodots in terms of their properties. Chem Sci. 2018;9(1):175-180. doi:10.1039/c7sc02528a

35. Qiao HZ, Sun MJ, Su ZG, et al. Kidney-specific drug delivery system for renal fibrosis based on coordination-driven assembly of catechol-derived chitosan. Biomaterials. 2014;35(25):7157-7171. doi:10.1016/j.biomaterials.2014.04.106

36. Hulin T, Koji N, Yoshiki H, et al. Cysteine SH and glutamate $\mathrm{COOH}$ contributions to $[\mathrm{NiFe}]$ hydrogenase proton transfer revealed by highly sensitive FTIR spectroscopy. Angew Chem Int Ed. 2019;58 (38):13285-13290. doi:10.1002/anie.201904472

37. Mantovani A, Allavena P, Sica A, et al. Cancer-related inflammation. Nature. 2008;454(7203):436-444. doi:10.1038/nature07205

38. Zhang XR, Chen L, Yuan L, et al. Conformation-dependent coordination of carboxylic acids with $\mathrm{Fe}_{3} \mathrm{O}_{4}$ nanoparticles studied by ART-FTIR spectral deconvolution. Langmuir. 2019;35 (17):5770-5778. doi:10.1021/acs.langmuir.8b03303

39. Wang HT, Wang W, Asif M, et al. Cobalt ion-coordinated self-assembly synthesis of nitrogen-doped ordered mesoporous carbon nanosheets for efficiently catalyzing oxygen reduction. Nanoscale. 2017;9(40):15534-15541. doi:10.1039/c7nr05208a

40. Liu Z, He W, Guo Z. Metal coordination in photoluminescent sensing. Chem Soc Rev. 2013;42(4):1568-1600. doi:10.1039/ c2cs35363f

41. Pandey R, Kumar A, Xu Q, et al. Zinc(II), copper(II) and cadmium(II) complexes as fluorescent chemosensors for cations. Dalton Trans. 2020;49(3):542-568. doi:10.1039/c9dt03017d

42. Goetzl EJ, Boxer A, Schwartz JB, et al. Altered lysosomal proteins in neural-derived plasma exosomes in preclinical Alzheimer disease. Neurology. 2015;85(1):40-47. doi:10.1212/WNL.0000000000001702

43. Almeida JPM, Chen AL, Foster A, et al. In vivo biodistribution of nanoparticles. Nanomedicine. 2011;6(5):815-825. doi:10.2217/ NNM.11.79

44. Liu J, Yu M, Ning X, et al. PEGylation and zwitterionization: pros and cons in renal clearance and tumor targeting of near-IR-emitting gold nanoparticles. Angew Chem Int Ed. 2013;125(48):12804-12808. doi:10.1002/ange.201304465

45. Wang WD, Li CL, Summer SN, et al. Role of AQP1 in endotoxemia-induced acute kidney injury. Am J Physiol-Cell Physiol. 2008;294(6):1473-1480. doi:10.1152/ajprenal.00036.2008 


\section{Publish your work in this journal}

The International Journal of Nanomedicine is an international, peerreviewed journal focusing on the application of nanotechnology in diagnostics, therapeutics, and drug delivery systems throughout the biomedical field. This journal is indexed on PubMed Central, MedLine, CAS, SciSearch ${ }^{\mathbb{B}}$, Current Contents ${ }^{\mathbb{B}} /$ Clinical Medicine,
Journal Citation Reports/Science Edition, EMBase, Scopus and the Elsevier Bibliographic databases. The manuscript management system is completely online and includes a very quick and fair peer-review system, which is all easy to use. Visit http://www.dovepress.com/ testimonials.php to read real quotes from published authors.

Submit your manuscript here: https://www.dovepress.com/international-journal-of-nanomedicine-journal 